Case report

\title{
Holmium YAG laser ablation of a hemangioma involving a lower pole renal calyx - using the new-generation flexible ureteroscope URF type $P 5^{\circledR}$ : a case report
}

\author{
Kogenta Nakamura $^{1}$, Yoshiaki Yamada ${ }^{1}$, Charles J Rosser ${ }^{2}$, Shigeyuki Aoki ${ }^{1}$, \\ Tomohiro Taki ${ }^{1}$ and Nobuaki Honda ${ }^{1}$
}

\begin{abstract}
Addresses: ${ }^{1}$ Department of Urology, Aichi Medical University School of Medicine, Nagakute-cho, Aichi 480-1195, Japan and ${ }^{2}$ Department of Urology, University of Florida, Gainesville, FL, USA

Email: KN* - kogenaka@aichi-med-u.ac.jp; YY - yy1124@aichi-med-u.ac.jp; CJR - Charles.Rosser@urology.ufl.edu;

SA - shige39@aichi-med-u.ac.jp; TT - tomotaki@aichi-med-u.ac.jp; NH - uro@aichi-med-u.ac.jp

* Corresponding author

Received: 22 August 2008 Accepted: 9 May 2009 Published: 17 June 2009

Cases Journal 2009, 2:7780 doi: 10.4076/1757-1626-2-7780

This article is available from: http://casesjournal.com/casesjournal/article/view/7780

(C) 2009 Nakamura et al; licensee Cases Network Ltd.

This is an Open Access article distributed under the terms of the Creative Commons Attribution License (http://creativecommons.org/licenses/by/3.0), which permits unrestricted use, distribution, and reproduction in any medium, provided the original work is properly cited.
\end{abstract}

\begin{abstract}
Hemangioma of the renal calyx is a rare disease, which is difficult to diagnose and an even greater challenge to treat. We report the use of the new-generation flexible ureteroscope, in the management of a 37-year-old Asian male with a lower pole renal calyx hemangioma, which was previously inaccessible.
\end{abstract}

\section{Introduction}

Renal hemangioma involving the collecting system is a rare disease [1] and is difficult to diagnose and treat. Previous reports discussed the need for a more radical approach (total or partial nephrectomy) to treat these hemangiomas. The need for less invasive surgery should be considered in this cohort. However, there have been significant advances in the technology related to ureteroscopy over the past decade, limited data are available for the use of endoscopic treatment of hemangiomas involving the collecting system. We report a case of a previously inaccessible lower pole calyx hemangioma that we gained access with the new-generation flexible ureteroscope, URF type P5 ${ }^{\circledR}$ (Olympus ${ }^{\mathrm{TM}}$ Corp., Tokyo, Japan), and effectively ablated the hemangioma with the Holmium YAG (HoYAG) laser.

\section{Case presentation}

A 37-year-old Asian male presented to his local urologist with a primary complaint of painless, gross, intermittent hematuria of two years duration. The previous urologist had performed and attempted ureteroscopy but was unable to fully examine the right collecting system. On presentation to our institute, the patient had abdominal ultrasonography, CT scanning and MRI, which demonstrated no abnormality. His urinary cytology was negative. Bloody efflux was observed from the right ureteral orifice on cystoscopy. The rest of the bladder appeared normal. Retrograde pyelogram of the right collecting system was within normal limits. The patient underwent right flexible ureteroscopy using flexible ureteroscope URF-P5. Dilation of the ureteral orifice was not necessary. The use of the URF type $P 5{ }^{\circledR}$ ureteroscope allowed maximum mobility within 


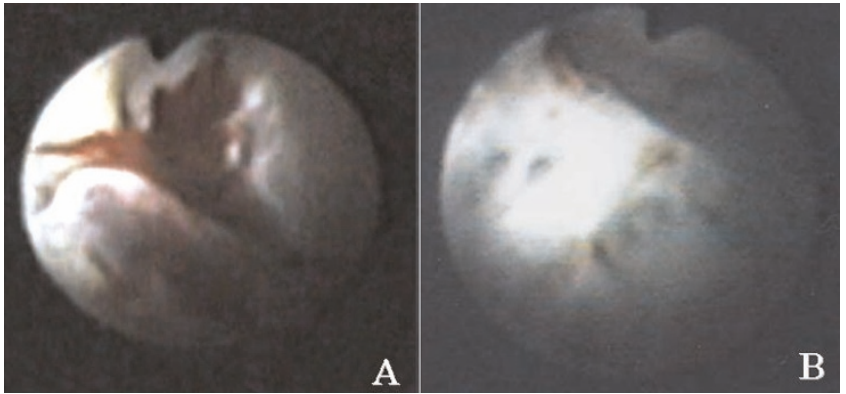

Figure I. Ureteroscopy showed a hemangioma (A). Findings after HoYAG laser ablation (B).

the collecting system. This combined with fluoroscopic examination of the right collecting system confirmed complete pyeloscopy. As a result, a hemangioma of the right lower pole renal calyx was identified (Figure 1A). No papillary masses or another other lesions or stones were identified in the collecting system. Subsequently, we employed the HoYAG laser (laser probe Lumenis $200 \mu \mathrm{m}$ and a laser generator Versa Plus $80 \mathrm{~W}$, Lumenis Inc., CA) to completely ablate this lesion in a rather bloodless field (laser settings- $0.5 \mathrm{~J}, 5 \mathrm{~Hz}$, total: $0.52 \mathrm{~kJ}$ ). At the conclusion of the case, a double J ureteral stent was placed. Two weeks later, the ureteral stent was removed. Here 15 months after the procedure, the patient is asymptomatic. Furthermore, microscopic urinalysis and urinary cytology are negative for blood or malignancy, respectively.

\section{Discussion}

Renal hemangioma is a rare disease and is difficult to diagnose. Daneshmand et al. reported the effectiveness of ureteroscopy and laser treatment [1]. They used a HoYAG laser or a neodymium YAG laser in 15 cases, and 11 of them were became symptom free (mean follow periods: 20.2 months) [1]. Though recent reports demonstrate how this entity can be handled endoscopically, a significant number of these patients will require repeat surgery. Recently, our institute started to use the new and smallerdiameter, URF type P5 ureteroscope, because of its improved maneuverability. As shown in Table 1 and Figure 2 , the URF type $\mathrm{P}^{\circledR}{ }^{\circledR}$ is superior in its angle of deflection compared to the URF type P3 ${ }^{\circledR}$. Both ureteroscopes are $8.9 \mathrm{Fr}$ in outer diameter, but the tip diameter of the URF type $\mathrm{P}^{\circledR}{ }^{\circledR}$ is $5.3 \mathrm{Fr}$, smaller than that of the URF type P3 ${ }^{\circledR}$, and therefore, smooth insertion can be expected. Kourambas et al. reported that $58 \%$ of cases needed dilation of the urinary tract [2]. The present case, however, did not require dilation of the urinary tract using a ureteral access sheath.

The URF type ${ }^{\circledR}{ }^{\circledR}$ has a smaller diameter than the URF type $\mathrm{P} 3^{\circledR}$, but has the same irrigant flow rate of approximately $37 \mathrm{ml} / \mathrm{min}$. However, as others have
Table I. Angles of deflection of URF-P3 and URF-P5

\begin{tabular}{|c|c|c|}
\hline Device & $\begin{array}{l}\text { URF-P3 } \\
\text { Down/Up }\left({ }^{\circ}\right)\end{array}$ & $\begin{array}{l}\text { URF-P5 } \\
\text { Down/Up }\left({ }^{\circ}\right)\end{array}$ \\
\hline Empty & $185 / 175$ & $275 / 180$ \\
\hline $\mathrm{Niic}^{\mathrm{a})} 250 \mu \mathrm{m}$ & $155 / 160$ & $265 / 165$ \\
\hline Niic $300 \mu \mathrm{m}$ & $135 / 135$ & $240 / 145$ \\
\hline Lumenis $^{\text {b) }} 200 \mu \mathrm{m}$ & $155 / 145$ & $245 / 150$ \\
\hline Lumenis $365 \mu \mathrm{m}$ & $100 / 100$ & $200 / 110$ \\
\hline FB-56D- $\left.\right|^{c)}$ & $155 / 150$ & $260 / 165$ \\
\hline
\end{tabular}

* It is not guarantee value.

a) Niic: Laser probe (Niic, Japan).

b) Lumenis: Laser probe (Lumenis, USA).

c) FB-56D-I: $3 \mathrm{Fr}$ biopsy forceps (Olympus ${ }^{\mathrm{TM}}$, Japan).

reported [3], with an increase in the number of uses, the decrease in irrigant flow rate and angle of deflection have to be taken into account. In addition, the smaller the diameter, the more faults that can occur, and an increase in cost may become a cause of concern [4]. This needs to be kept in mind when treating patients.

\section{Conclusion}

We report on the use of the new-generation flexible ureteroscope, URF type P5 ${ }^{\circledR}$ (Olympus ${ }^{\mathrm{TM}}$ ) in the management of a patient with a lower pole renal calyx hemangioma which was previously inaccessible.

\section{List of abbreviations}

CT, Computed Tomography; MRI, Magentic Resonance Imaging.

A

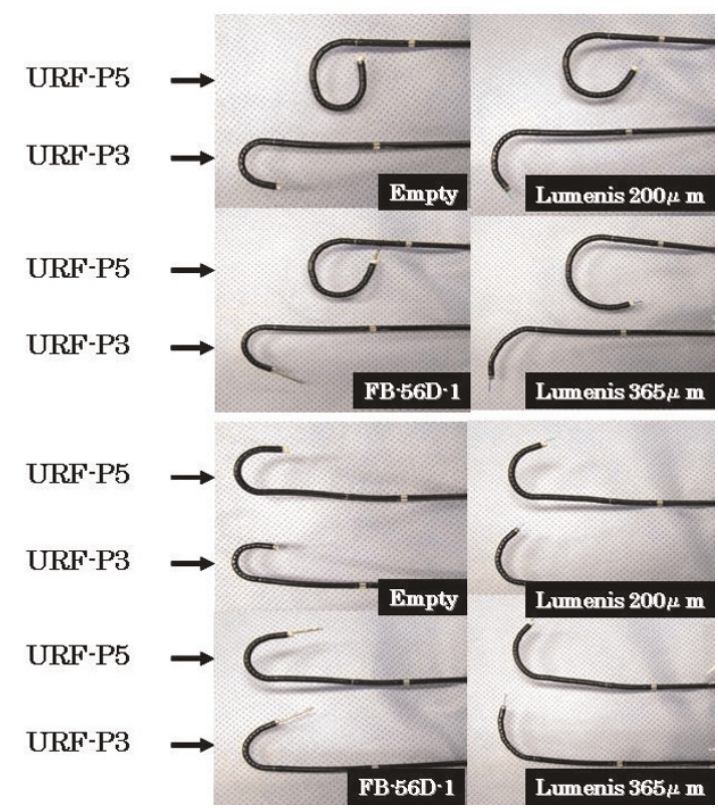

Figure 2. Angles of deflection of URF-P3 and URF-P5. Down angles (A), Up angles (B). 


\section{Consent}

Written informed consent was obtained from the patient for publication of this case report and accompanying images. A copy of the written consent is available for review from the journal's Editor-in-Chief.

\section{Competing interests}

The authors declare that they have no competing interests.

\section{Authors' contributions}

KN cared for the patient, drafted the report, and approved the final version of the manuscript. YY cared the patient, drafted the report, and approved the final version of the manuscript. CJR reviewed the ureteroscopic findings of hemangioma and photo of ureteroscopy, and approved the final version of the manuscript. SA cared for the patient, rafted the report, and approved the final version of the manuscript. TT cared for the patient, rafted the report, and approved the final version of the manuscript. NH ared for the patient, rafted the report, and approved the final version of the manuscript.

\section{References}

I. Daneshmand S, Huffman JL: Endoscopic management of renal hemangioma. J Urol 2002, 167:488-489.

2. Kourambas J, Byrne RR, Preminger GM: Does a ureteral access sheath facilitate ureteroscopy? J Urol 200I, 165:789-793.

3. Traxer O, Dubosq F, Jamali K, Gattegno B, Thibault P: Newgeneration flexible ureterorenoscopes are more durable than previous ones. Urology 2006, 68:276-279.

4. Landman J, Lee DI, Lee C, Monga M: Evaluation of overall costs of currently available small flexible ureteroscopes. Urology 2003, 62:218-222.

\section{Do you have a case to share?}

Submit your case report today

- Rapid peer review

- Fast publication

- PubMed indexing

- Inclusion in Cases Database

Any patient, any case, can teach us something

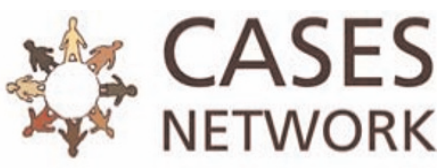

www.casesnetwork.com 